\title{
Beta cell nuclear musculoaponeurotic fibrosarcoma oncogene family A (MafA) is deficient in type 2 diabetes
}

\author{
A. E. Butler • R. P. Robertson • R. Hernandez • \\ A. V. Matveyenko • T. Gurlo • P. C. Butler
}

Received: 6 June 2012 / Accepted: 3 July 2012 / Published online: 31 July 2012

(C) Springer-Verlag 2012

\begin{abstract}
Aims/hypothesis The beta cell transcriptional factor musculoaponeurotic fibrosarcoma oncogene family A (MafA) regulates genes important for beta cell function. Loss of nuclear MafA has been implicated in beta cell dysfunction in animal models of type 2 diabetes. We sought to establish if nuclear MafA is less abundant in beta cell nuclei in humans with type 2 diabetes.

Methods Pancreas obtained at surgery from five nondiabetic individuals and six individuals with type 2 diabetes was immunostained for insulin, glucagon and MafA.

Results Beta cell nuclear MafA was markedly decreased in type 2 diabetes $(1.6 \pm 1.2 \%$ vs $46.3 \pm 8.3 \%, p<0.001)$.

Conclusions/interpretation Beta cell nuclear MafA is markedly decreased in humans with type 2 diabetes, which may contribute to impaired beta cell dysfunction.
\end{abstract}

Keywords Beta cell $\cdot$ Glucotoxicity $\cdot$ MafA

Abbreviation
MafA Musculoaponeurotic fibrosarcoma oncogene
$\quad$ family A

A. E. Butler • R. Hernandez - A. V. Matveyenko - T. Gurlo •

P. C. Butler $(\square)$

Larry Hillblom Islet Research Center,

UCLA David Geffen School of Medicine,

900 Veteran Avenue, 24-130 Warren Hall,

Los Angeles, CA 90095-7073, USA

e-mail: pbutler@mednet.ucla.edu

R. P. Robertson

Pacific Northwest Diabetes Research Institute and Division of

Metabolism, Endocrinology, and Nutrition, Departments of

Medicine and Pharmacology, University of Washington,

Seattle, WA, USA

\section{Introduction}

Impaired insulin secretion in type 2 diabetes is, at least in part, a consequence of glucotoxicity mediated through chronic hyperglycaemia [1].

One proposed mechanism for impaired insulin secretion mediated by chronic hyperglycaemia is through the action of oxidative stress to disrupt nuclear binding of the beta cell transcriptional factor musculoaponeurotic fibrosarcoma oncogene family A (MafA) [2-4]. MafA acts as a transcriptional regulator that promotes the expression of genes important in glucose-induced insulin secretion, such as insulin, glucokinase and glucose transporter protein-2 [5]. In rodents MafA production in islets is confined to beta cells, where it is localised to the nucleus in $\sim 80 \%$ of beta cells by birth, a percentage that is retained in adult life [6].

While loss of beta cell nuclear MafA has been described in diabetic rodent models [4], we are unaware of similar studies in humans with type 2 diabetes. Therefore, in the present study we examined pancreas obtained at surgery from humans with and without type 2 diabetes to detect the beta cell levels and subcellular localisation of MafA by immunohistochemistry. We thus tested the hypothesis that the proportion of beta cells with detectable nuclear MafA is decreased in type 2 diabetes.

\section{Methods}

Participants Samples of pancreas were collected at the time of surgery at the University of California Los Angeles Medical Center (IRB \# 99-05-085-14). These individuals were undergoing pancreatic surgery for the removal of tumour masses (see Table 1) and the sample of pancreas obtained for research was distant and distinct from the tumour. Five non- 
Table 1 Characteristics of participants

\begin{tabular}{|c|c|c|c|c|c|c|c|}
\hline Group & $\begin{array}{l}\text { Duration of } \\
\text { diabetes (years) }\end{array}$ & $\begin{array}{l}\text { Age } \\
\text { (years) }\end{array}$ & Sex & BMI & $\begin{array}{l}\text { FBG } \\
(\mathrm{mmol} / \mathrm{l})\end{array}$ & Surgery & Reason for surgery \\
\hline \multicolumn{8}{|c|}{ Non-diabetic } \\
\hline 1 & N/A & 67 & M & 24 & 4.3 & Whipple & Adenocarcinoma head of pancreas \\
\hline 2 & N/A & 55 & M & 28 & 4.5 & Whipple & Adenocarcinoma head of pancreas \\
\hline 3 & N/A & 70 & $\mathrm{~F}$ & 25 & 4.6 & Whipple & Cholangiocarcinoma, chronic pancreatitis \\
\hline 4 & N/A & 64 & M & 30 & 5.3 & Whipple & Adenocarcinoma head of pancreas \\
\hline 5 & N/A & 67 & $\mathrm{~F}$ & 30 & 5.7 & Whipple & $\begin{array}{l}\text { Adenocarcinoma head of pancreas, } \\
\text { chronic pancreatitis }\end{array}$ \\
\hline Mean & & 65 & & 27 & 4.9 & & \\
\hline SEM & & 3 & & 1 & 0.3 & & \\
\hline \multicolumn{8}{|c|}{ Type 2 diabetic } \\
\hline 1 & 1 & 71 & M & 25 & 6.3 & Whipple & $\begin{array}{l}\text { Adenocarcinoma head of pancreas, } \\
\text { chronic pancreatitis }\end{array}$ \\
\hline 2 & $<4$ & 65 & $\mathrm{~F}$ & 31 & 5.8 & Middle pancreatectomy & Benign lymphoepithelial cyst \\
\hline 3 & Unknown & 64 & M & 21 & 14.9 & Whipple & Adenocarcinoma head of pancreas \\
\hline 4 & 12 & 56 & $\mathrm{~F}$ & 36 & 8.9 & $\begin{array}{l}\text { Distal pancreatectomy/ } \\
\text { splenectomy }\end{array}$ & Adenocarcinoma head of pancreas \\
\hline 5 & $0^{\mathrm{a}}$ & 69 & M & 32 & 8.3 & Whipple & $\begin{array}{l}\text { Intraductal papillary neoplasm, } \\
\text { chronic pancreatitis }\end{array}$ \\
\hline 6 & 0.25 & 64 & $\mathrm{~F}$ & 23 & 11.4 & Whipple & Mass, head of pancreas \\
\hline Mean & & 65 & & 28 & 9.3 & & \\
\hline SEM & & 2 & & 2 & 1.4 & & \\
\hline
\end{tabular}

${ }^{\text {a }}$ New onset

F, female; M, male; N/A, not appropriate

diabetic participants (fasting blood glucose $4.9 \pm 0.3 \mathrm{mmol} / \mathrm{l}$ ) and six individuals with documented type 2 diabetes (fasting blood glucose $9.3 \pm 1.4 \mathrm{mmol} / \mathrm{l}$ ) were included in the study. The reported blood glucose values are the fasting blood glucoses obtained in the week prior to surgery. The two groups were well matched by age ( $65 \pm 3$ vs $65 \pm 2$ years, non-diabetic vs type 2 diabetes) and body mass index ( $27 \pm 1 \mathrm{vs} 28 \pm 2 \mathrm{~kg} / \mathrm{m}^{2}$, non-diabetic vs type 2 diabetes).

Pancreas collection Each pancreatic sample obtained during surgery was immediately fixed, in the operating room, in $4 \%$ (vol./vol.) formaldehyde in PBS for $24 \mathrm{~h}$ at $4{ }^{\circ} \mathrm{C}$, then placed into $70 \%$ (vol./vol.) alcohol for another $24 \mathrm{~h}$ at $4{ }^{\circ} \mathrm{C}$ before processing and embedding in paraffin. For the purposes of this study, a sample of pancreas remote from the tumour was selected.

Human-embryonic-stem-cell-derived endoderm In a previous report we described the outcome of studies in which human-embryonic-derived pancreatic endoderm was transplanted into epididymal fat pads of athymic rats and retrieved 20 weeks later. Islet-like clusters of insulinexpressing cells were present in some cases [7]. Permission for these studies was obtained from the UCLA Institutional
Animal Care and Embryonic Stem Cell Research Oversight Research Committees. We examined sections of three extracted fat pads from that previously published study in which the highest number of newly formed insulinexpressing cells were present to evaluate the newly formed beta cells for MafA levels and nuclear localisation.

Immunofluorescence One section of pancreas per case $(4 \mu \mathrm{m})$ was immunostained for insulin, glucagon and MafA. The following primary antibodies were used: guinea pig anti-insulin 1:100 (Invitrogen, Carlsbad, CA, USA); mouse anti-glucagon 1:500 (Sigma-Aldrich, St Louis, MO, USA); and rabbit anti-MafA 1:5,000 (Abcam, Cambridge, MA, USA). The following secondary antibodies were used: FITC donkey anti-guinea pig 1:100 (Jackson ImmunoResearch Laboratories, West Grove, PA, USA); Cy5 donkey antiMouse 1:100 (Jackson ImmunoResearch Laboratories); horseradish peroxidase-coupled goat anti-rabbit 1:1,000 (Invitrogen). The Tyramide Signal Amplication system (TSA) (Perkin Elmer, Waltham, MA, USA) was used to amplify the MafA signal. The immunofluorescence-stained sections were coverslipped with Vectashield with DAPI to provide a nuclear stain (Vector Laboratories, Burlingame, CA, USA). 
It is noted that the immunostaining for MafA in humans only provided a specific nuclear pattern, as previously reported in animal studies, in pancreas procured at surgery and immediately fixed. Pancreas obtained at autopsy or from brain-dead organ donors from the Network for Pancreatic Organ Donors with Diabetes (nPOD) programme did not provide specific immunostaining for MafA by the methods employed here, implying that the integrity of this protein may be short-lived after pancreas resection. On the other hand, in a recent study MafA was detected in $55 \%$ of beta cells in pancreas sections of a brain-dead organ donor as well as in isolated islets [8].

Analysis Immunofluorescent-stained sections were viewed using a Leica DM6000 microscope (Leica, Deerfield, IL, USA) connected to a Macintosh computer loaded with Openlab software (Improvision, Lexington, MA, USA). Images were taken at $\times 20$ magnification.

For each imaged islet, the total number of beta cells was determined as well as the number of those beta cells that had positive nuclear staining for the MafA antibody. An average of 28 islets (range 25 to 30 islets) were analysed from each of the five non-diabetic cases, and an average of 26 islets (range 23 to 28 islets) were analysed from each of the individuals with type 2 diabetes. This gave a mean of 676 beta cells (range 371 to 1,100 beta cells) analysed per individual in the non-diabetic group and a mean of 731 beta cells (range 266 to 1,668 beta cells) analysed per individual in the group with type 2 diabetes.

From the three extracted fat pads containing human embryonic stem cells, a mean of 644 insulin-positive cells were analysed per case (range 14 to 1,137 cells).

Statistical analysis Data were compared using the twotailed unpaired Student's $t$ test and presented as means \pm SEM. A value of $p<0.05$ was taken to be statistically significant.

\section{Results}

MafA nuclear staining was prominent in $46.3 \pm 8.3 \%$ of pancreatic beta cell nuclei in non-diabetic individuals (Fig. 1). As previously reported in rodent studies MafA production detected by immunostaining was confined to beta cells within the islet, alpha cells being negative. In contrast to non-diabetic controls, MafA nuclear staining of beta cells in the pancreatic islets of individuals with type 2 diabetes was markedly reduced at $1.6 \pm 1.2 \%$ ( $p<0.001$ compared with non-diabetic individuals). MafA was detected in $54.2 \pm 7.4 \%$ of the nuclei of insulin-expressing cells in the islet-like structures in the fat-pad-implanted human embryonic stem cell pancreatic endoderm.

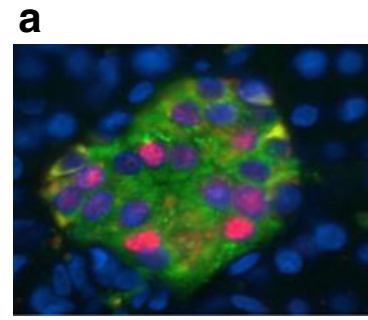

C
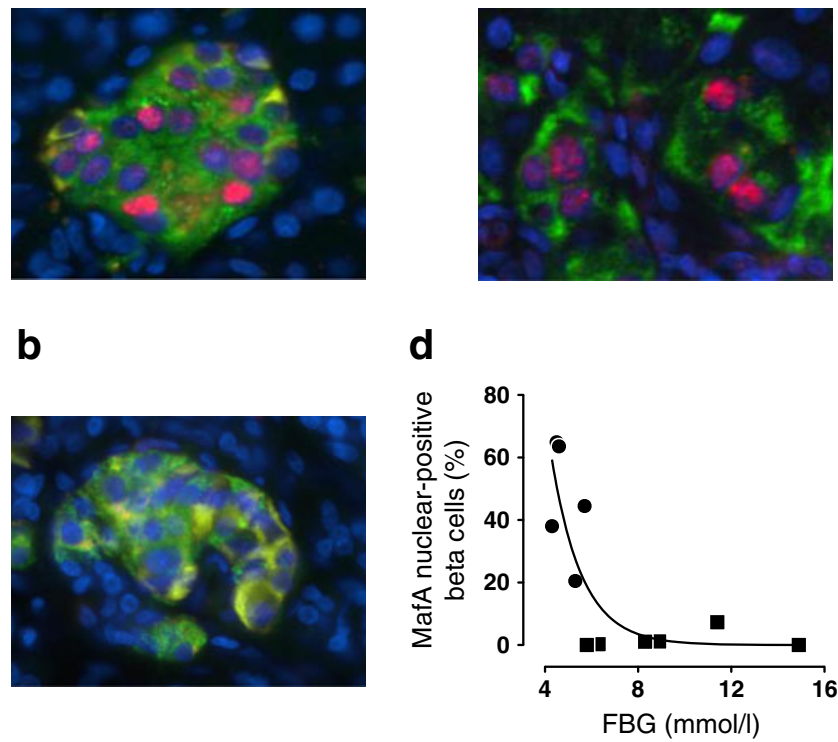

Fig. 1 (a) A representative pancreatic islet from a non-diabetic participant (non-diabetic participant 3 ) and (b) a representative islet from an individual with type 2 diabetes (type 2 diabetes participant 1) stained for insulin (green), glucagon (yellow), MafA (red) and DAPI (blue). Nuclear localisation of MafA is present in many, but not all, of the beta cell nuclei in the islet from the non-diabetic individual. In contrast, nuclear MafA is rarely detected in the beta cells of the participant with type 2 diabetes, and no MafA-positive nuclei are seen in this example. (c) Human embryonic stem cells stained for insulin (green), MafA (red) and DAPI (blue) show many, but not all, nuclei of beta cells staining for MafA. (d) The relationship between fasting blood glucose and the percentage of beta cell nuclei staining for MafA in non-diabetic individuals (circles) and individuals with type 2 diabetes (squares). FBG, fasting blood glucose

\section{Discussion}

Consistent with a role of glucotoxicity in impaired beta cell function in type 2 diabetes, we report that nuclear-localised MafA is markedly decreased in humans with type 2 diabetes.

It is of interest that the percentage of beta cells with MafA-detectable beta cells is lower in non-diabetic humans $(\sim 45 \%)$ than in non-diabetic rodents $(\sim 80 \%)$. As this might be an age-dependent effect we also examined the percentage of beta cells positive for nuclear MafA in human embryonic beta cells programmed to favour endocrine development and implanted in immunodeficient rats. The percentages of beta cells with nuclear-localised MafA were comparable in insulin-expressing cells derived from human embryonic stem cells $(\sim 54 \%)$ and adult humans, suggesting that in humans there may be a subset of beta cells that do not maintain nuclear MafA. This is also consistent with a previous report of $\sim 55 \%$ beta cells positive for MafA in the pancreas of a non-diabetic brain-dead donor and in isolated human islets [8]. From these studies it is not possible to determine the functional significance of these apparently 
distinct populations of beta cells with and without nuclear localisation of MafA in non-diabetic humans. At least by insulin immunohistochemistry there was no clear difference between the two populations of cells, and the proportion of cells with nuclear localisation of MafA tended to be similar in islets within an individual. It has been previously reported that there is heterogeneity between beta cells in glucose responsiveness [9], so it is plausible that cells that do not have nuclear MafA are relatively glucose unresponsive when compared with those that do.

The marked decrease in beta cell nuclear MafA detected in individuals with type 2 diabetes is consistent with animal models of type 2 diabetes [4]. However, given the small group of individuals available, it is not feasible to undertake a subanalysis of factors that may influence beta cell nuclear MafA detection, such as diabetes therapy, duration of diabetes or diabetes control. Moreover, as the percentage of beta cells with detectable nuclear MafA was markedly decreased in all individuals with type 2 diabetes, it is unlikely that subanalysis would be insightful unless very large numbers of cases were available.

The reason that so few cases were available in this study relates to a technical issue. We established that immunohistochemical detection of MafA in human pancreas is not possible unless the pancreas is immediately fixed on resection at surgery, i.e. taken from a living individual. Pancreas procured from autopsy, even before any detectable autolysis, did not have any detectable beta cell MafA on immunohistochemistry using the same antibody and protocol. Moreover, MafA could not be detected immunohistochemically in pancreas resected at surgery and not fixed immediately in the operating room but rather processed routinely for pathology.

In conclusion, MafA was detected in the nuclei of $\sim 45 \%$ of pancreatic beta cells in non-diabetic human adults. This is a similar proportion of beta cells positive for MafA in insulin-expressing cells present in human pancreatic endoderm directed towards an endodermal lineage. We report a marked decrease in beta cells with nuclear MafA in pancreatic samples from individuals with type 2 diabetes. This state may contribute to hyperglycaemia-induced impaired insulin secretion in diabetes.

Acknowledgements We gratefully acknowledge the editorial assistance of B. Lui (UCLA, Los Angeles, CA, USA).
Funding This study was funded by the National Institutes of Health (DK077967, DK059579, DK061539 to PCB and DK032585 to RPR) and the Larry L. Hillblom Foundation.

Contribution statement AEB undertook the morphometric analysis. TG collected tissue and supervised the immunostaining procedures. $\mathrm{RH}$ performed the immunostaining procedure. AVM undertook the studies of human embryonic-stem-cell-derived implantation and procured the fat-pad-implanted samples used here.

AEB, TG, AVM, RPR and PCB made substantial contributions to the conception and design of the study. AEB, RH and AVM collected data, and AEB and PCB analysed and interpreted the data. AEB and PCB drafted the article. All authors revised the article critically for important intellectual content and gave final approval of the version to be published.

Duality of interest The authors declare that there is no duality of interest associated with this manuscript.

\section{References}

1. Robertson RP (2004) Chronic oxidative stress as a central mechanism for glucose toxicity in pancreatic islet beta cells in diabetes. J Biol Chem 279:42351-42354

2. Harmon JS, Stein R, Robertson RP (2005) Oxidative stressmediated, post-translational loss of MafA protein as a contributing mechanism to loss of insulin gene expression in glucotoxic beta cells. J Biol Chem 280:11107-11113

3. Wang H, Brun T, Kataoka K, Sharma AJ, Wollheim CB (2007) MAFA controls genes implicated in insulin biosynthesis and secretion. Diabetologia 50:348-358

4. Harmon JS, Bogdani M, Parazzoli SD et al (2009) Beta-cell-specific overexpression of glutathione peroxidase preserves intranuclear MafA and reverses diabetes in $\mathrm{db} / \mathrm{db}$ mice. Endocrinology 150:4855-4862

5. Zhang C, Moriguchi T, Kajihara M et al (2005) MafA is a key regulator of glucose-stimulated insulin secretion. Mol Cell Biol 25:4969-4976

6. Nishimura W, Kondo T, Salameh T et al (2006) A switch from MafB to MafA expression accompanies differentiation to pancreatic betacells. Dev Biol 293:526-539

7. Matveyenko AV, Georgia S, Bhushan A, Butler PC (2010) Inconsistent formation and nonfunction of insulin-positive cells from pancreatic endoderm derived from human embryonic stem cells in athymic nude rats. Am J Physiol Endocrinol Metab 299:E713-E720

8. Dai C, Brissova M, Hang Y et al (2012) Islet-enriched gene expression and glucose-induced insulin secretion in human and mouse islets. Diabetologia 55:707-718

9. Salomon D, Meda P (1986) Heterogeneity and contact-dependent regulation of hormone secretion by individual B cells. Exp Cell Res 162:507-520 